\title{
Progressive myoclonic epilepsy type 9
}

INSERM

\section{Source}

INSERM. (1999). Orphanet: an online rare disease and orphan drug data base.

Progressive myoclonic epilepsy type 9. ORPHA:457265

A rare, genetic, neurological disorder characterized by childhood-onset severe myoclonic and tonic-clonic seizures and early-onset ataxia leading to severe gait disturbances associated with normal to slightly diminished cognition. Scoliosis, diffuse muscle atrophy and subcutaneous fat loss, as well as developmental delay, may be associated. Brain MRI may reveal complete agenesis of the corpus callosum, venticulomegaly, interhemispheric cysts, and simplified gyration (frontally). 